\title{
Linfoma Extranodal de Células T/NK en Cavidad Oral. Reporte de un Caso en Chile
}

\author{
Extranodal Lymphoma of T/NK Cells in Oral Cavity. Case Report in Chile \\ Humeres Sigala Carlos'; Espinoza Iris²; Lillo Felipe'; Baksai Karol ${ }^{4} \&$ Araya Cristobal ${ }^{5}$
}

HUMERES, S. C.; ESPINOZA, I.; LILLO, F.; BAKSAI, K. \& ARAYA, C. Linfoma extranodal de células T/NK en cavidad oral. Reporte de un caso en Chile. Int. J. Odontostomat., 13(4):398-401, 2019.

RESUMEN: El linfoma extranodal de células T/NK es una neoplasia maligna agresiva que se caracteriza por una destrucción de estructuras de la línea media de la cara como paladar y fosa nasal. Presentamos el caso de un paciente de sexo masculino, 48 años de edad, consumidor de cocaína, que consulta en la Facultad de Odontología de la Universidad de Chile en Septiembre del 2015 por síntomas de disfagia, rinorrea y que presenta al examen clínico un tumor ulcerado que compromete paladar duro y blando, de un mes de evolución. Se confirma diagnóstico de linfoma de células T/NK con una batería de pruebas inmunohistoquímicas. Esta patología, aunque infrecuente, siempre debe ser considerada dentro los diagnósticos diferenciales en tumores ulcerados en esta localización.

PALABRAS CLAVE: linfoma, cavidad oral, células killers.

\section{INTRODUCCIÓN}

El linfoma de células T/NK es una neoplasia maligna de baja frecuencia caracterizada por destrucción de los tejidos de fosa nasal y paladar, comportamiento agresivo y mal pronóstico (Neville et al., 2015). Por varias décadas su naturaleza fue controversial y recibió diversas denominaciones como Granuloma centrofacial, Linfoma de células T angiocéntrico, Granuloma letal de la línea media, Reticulosis polimorfa, entre otros (Norris et al., 2012).

\section{REPORTE DEL CASO}

Paciente hombre de 48 años solicita atención en la Clínica de Medicina Oral de la Facultad de Odontología de la Universidad de Chile en Septiembre del 2016 por dolor al tragar desde hace un mes. El paciente no relata antecedentes mórbidos ni consumo de medicamentos; entre sus hábitos indica fumar 10 cigarrillos diarios desde hace 28 años y haber consumido drogas duras, pasta base de cocaína, por aproximadamente 20 años. En la anamnesis próxima presenta disfagia, rinorrea con descarga posterior, adinamia, sudoración y fiebre nocturna.

Al examen físico presenta linfoadenopatías cervicales (grupo II) bilaterales, levemente dolorosas, fijas a planos profundos (Fig. 1). En el examen intraoral, se observa una extenso tumor de paladar ulcerado, en su parte anterior de consistencia blanda cubierto por mucosa eritematosa y en su parte posterior destaca necrosis y una comunicación oronasal; además, se aprecia lengua depapilada (Fig. 2). Se indican exámenes complementarios biopsia incisional, tomografía axial computarizada (TAC), hemograma, perfil bioquímico, y pruebas serológicas para descartar Sífilis (VDRL) y test de ELISA para detectar anticuerpos anti- virus de Inmunodeficiencia Humana $(\mathrm{VIH})$.

\footnotetext{
${ }^{1}$ Especialista en Patología Buco Máxilofacial, Hospital de Antofagasta, Chile.

${ }^{2}$ Especialista en Patología Bucomáxilofacial, Jefa del Área de Anatomía Patológica de la Facultad de Odontología de la Universidad de Chile, Chile.

${ }^{3}$ Especialista en Patología Buco Máxilofacial, Hospital San José, Chile.

${ }^{4}$ Especialista en Anatomía Patológica, Servicio Anatomía Patológica del Hospital Barros Luco Trudeau, Santiago, Chile

${ }^{5}$ Especialista en Patología Buco Máxilofacial, Staff Equipo Cabeza y Cuello, Instituto Nacional del Cáncer, Chile.
} 


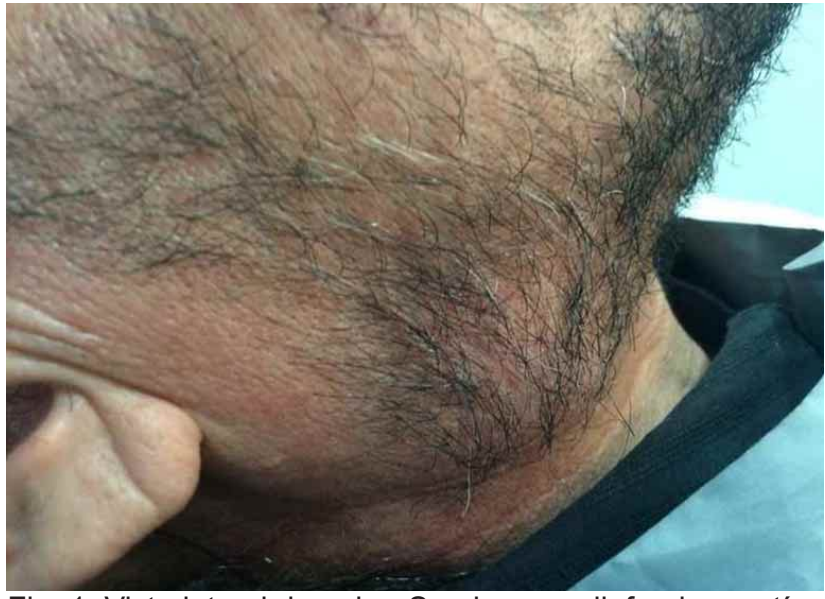

Fig. 1. Vista lateral derecha. Se observan linfoadenopatías en grupo II.

Se establecen como posibles diagnósticos una perforación palatina por uso de cocaína, linfoma y carcinoma oral de células escamosas.

\section{Los resultados de los exámenes indican:}

TAC: Masa sólida heterogénea. Aspecto neoplásico, contornos mal definidos. Ubicación centrada a nivel de rinofaringe con compromiso de paladar blando y erosión de paladar duro. Obstrucción de drenaje de senos paranasales. A nivel de cuello se observan múltiples adenopatías cervicales bilaterales, formando conglomerados en grupos II y III alcanzando la mayor aproximadamente 3,7 por $3 \mathrm{~cm}$. Estructuras heterogéneas con centro necrótico (Fig. 3).

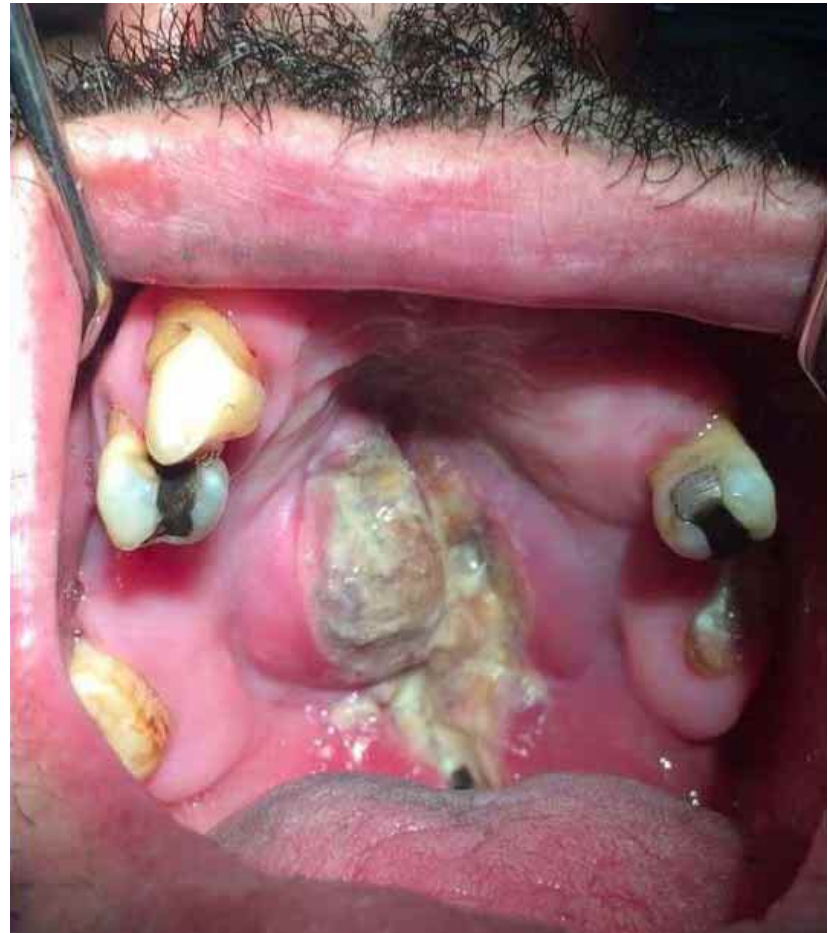

Fig. 2. Vista intraoral. Lesión tumoral palatina con extensa necrosis y comunicación oronasal.

Exámenes de sangre: VIH y VDRL negativos. Hemograma y perfil bioquímico normales.

El estudio histopatológico de biopsia incisional describe un infiltrado linfoide atípico neoplásico acompañado de un abundante infiltrado mixto de células inflamatorias y áreas de necrosis. Las células
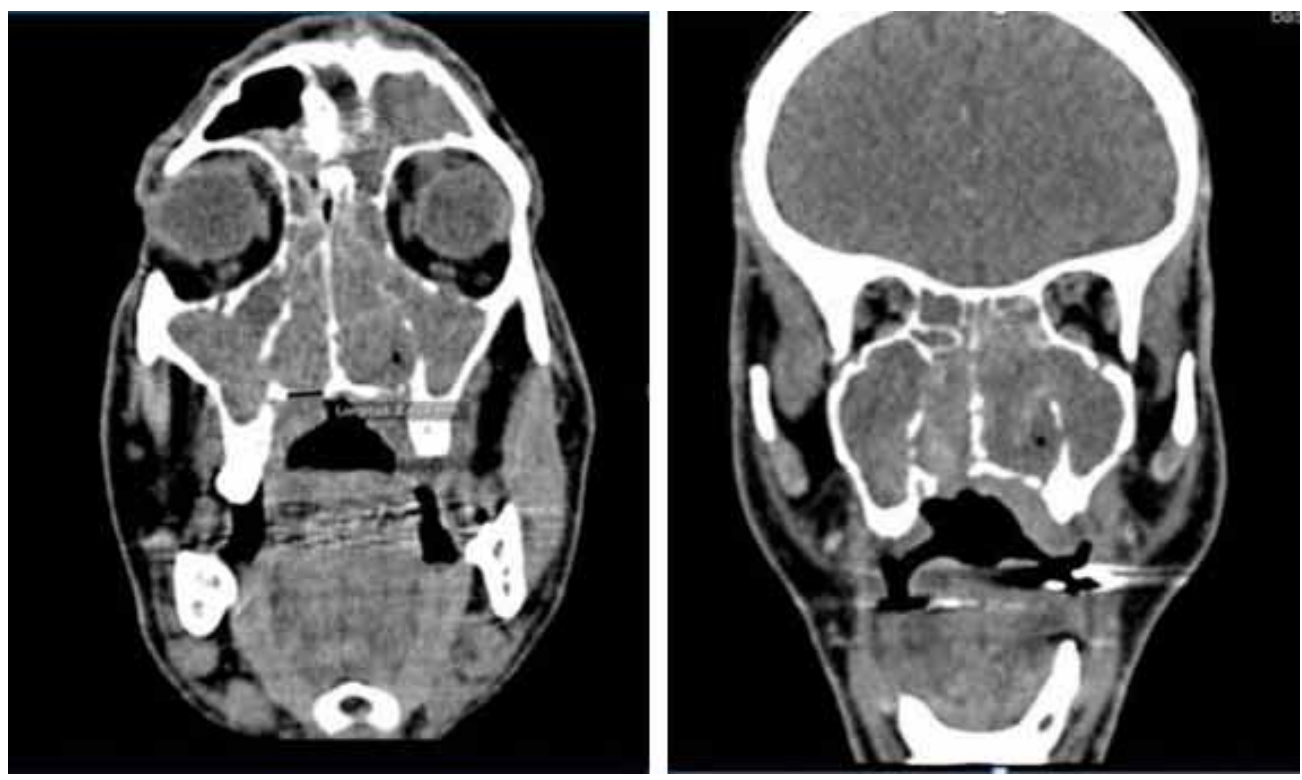

Fig. 3. TAC de macizo máxilofacial. A. Se observa pérdida de continuidad de cortical de piso de fosa nasal derecha. B. Obstrucción de drenaje de senos maxilares y se aprecia lesión destructiva. 
neoplásicas eran de tamaño intermedio a grandes con anisocitosis e hipercromasia nuclear. Estudio inmunohistoquímico muestra predominio de positividad para CD3(+), marcador de células $T$ maduras; CD56(+) marcador de células Natural Killer; y CD8(+) marcador de células T Citotóxicas, sólo en cerca del $30 \%$ del infiltrado (Fig. 4). Por otra parte, negativo para marcadores CD20, CD15, PAX5 y BLC-6

Se concluye diagnóstico de Linfoma no Hodgkin de células T/NK. El paciente se derivó a Servicio de Oncología para tratamiento. Sin embargo, fallece 90 días posteriores al diagnóstico.

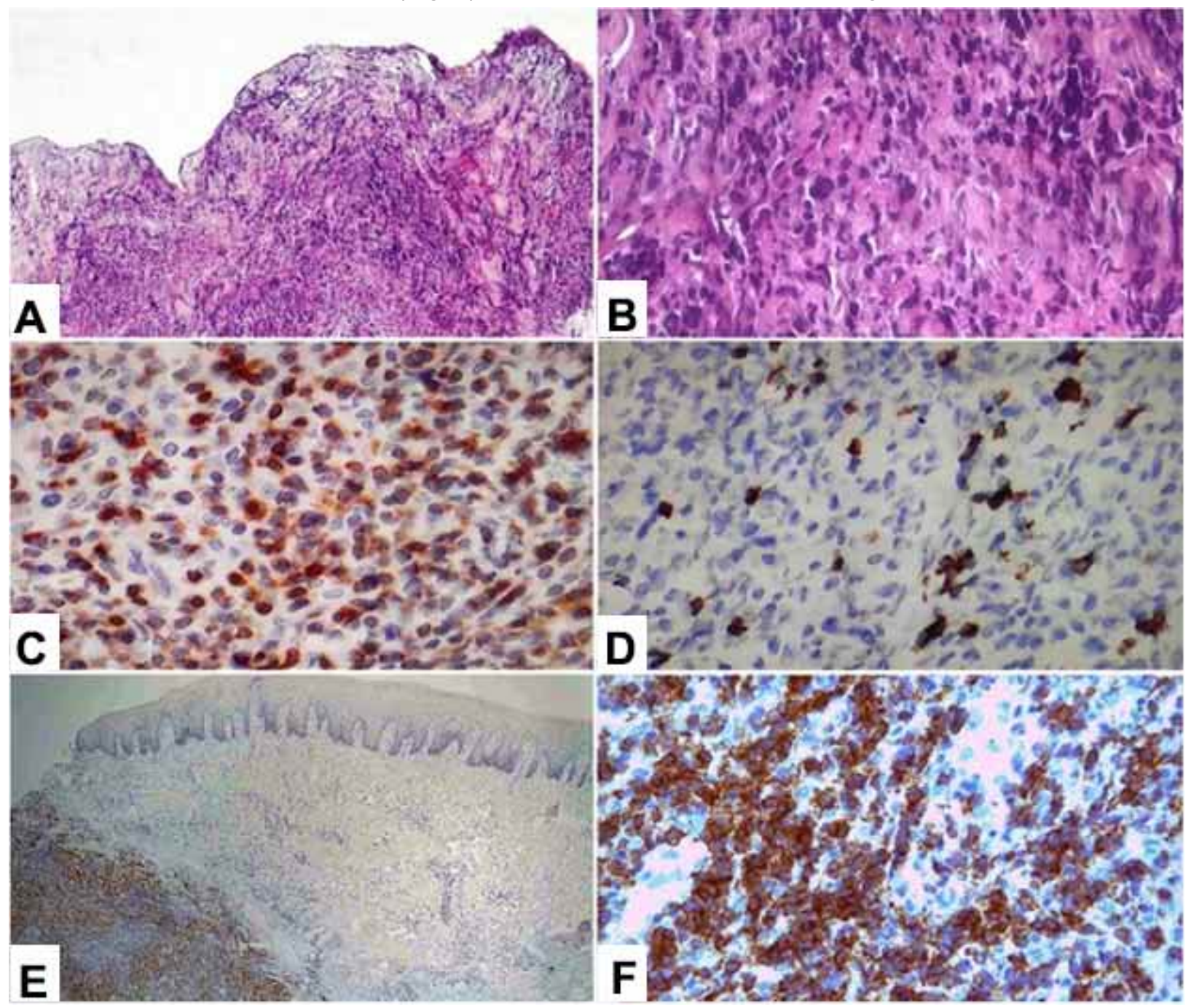

Fig. 4. Histopatología A: Proliferación linfocítica atípica, tinción H-E (4x). B. Anisocitosis, mitosis atípica e hipercromatismo nuclear, tinción H-E (10x). C CD3 (+ ) para celulas neoplásicas, marcador de células T. D: CD8(+) marcador de células T Citotóxicas. E y F: CD56 (+) marcador de células Natural Killer.

\section{DISCUSIÓN}

La clasificación de la Organización Mundial de la Salud (OMS) clasifica esta neoplasia en la categoría de neoplasia de células T maduras y células NK, linfoma T/NK extraganglionar, de tipo nasal (Norris et al.), y describe que se diagnóstica más frecuentemente en adultos y de género masculino.
Esta neoplasia se caracteriza por una presentación clínica inicial inespecífica con secreción nasal, sinusitis, inflamación facial y epistaxis; y a medida que se desarrolla el tumor se produce, comúnmente, destrucción de estructuras de la línea media, necrosis de senos paranasales con extensión palatina y formación 
de comunicación oronasal (Milián et al., 2001; Hmidi et al., 2013). Para el caso reportado, se consideró como diagnóstico diferencial, la perforación palatina por uso de cocaína (Silvestre et al., 2010), debido a que era un hábito presente en este paciente, y el carcinoma escamoso de células escamosas, aunque su localización en paladar es poco frecuente. Diagnósticos diferenciales que pueden presentarse como lesiones destructivas en la línea media de paladar son Granulomatosis de Wegener, Sífilis terciaria y otras causas infecciosas (TIholoe et al., 2013), como Leishmaniasis, Histoplasmosis, Tuberculosis y Lepra; además, de Sialometaplasia necrotizante del paladar.

La causa de este linfoma todavía es incierta, sin embargo, creciente evidencia menciona que el Virus Epstein-Barr (VEB) tendría un rol en la patogenia (Haverkos et al., 2017). La carga viral circulante de VEB se ha asociado con la extensión de la lesión, pobre respuesta a la terapia y mal pronóstico. En Chile, se detectado VEB en linfomas nasales de células T/ NK y se ha sugerido que una nueva cepa recombinante tipo "i"/Xhol podría contribuir a explicar la incidencia intermedia, menor que en Asia, que es la zona con la mayor incidencia a nivel global (Cabrera et al., 2007).

Finalmente, es relevante destacar que este linfoma posee un carácter agresivo y un pronóstico pobre con una tasa de sobrevida de $30-40 \%$. La adición de quimioterapia para las etapas avanzadas no parece mejorar la sobrevida en comparación con la radioterapia sola, que sigue siendo el tratamiento de elección, especialmente para los estadios localizados (Tababi et al., 2015).

Concluimos la presentación de un caso de Linfoma extranodal de células T/NK con diagnóstico tardío lo que terminó en la temprana muerte posterior al diagnóstico por lo destacamos la necesidad de diagnóstico en estadíos tempranos.

HUMERES, S. C.; ESPINOZA, I.; LILLO, F.; BAKSAI, K. \& ARAYA, C. Extranodal lymphoma of T / NK cells in oral cavity. Case report in Chile. Int. J. Odontostomat., 13(4):398-401, 2019.

ABSTRACT: Extranodal T / NK cell lymphoma is an aggressive malignant neoplasm characterized by destruction of midline structures of the face such as the palate and nasal fossa. We present the case of a male patient, 48 years old, cocaine user, who consults at the Faculty of Dentistry of the Universidad de Chile in September of 2015 due to symptoms of dysphagia, rhinorrhea and presenting to the clinical examination an ulcerated tumor which compromises hard and soft palate, a month of evolution. Diagnosis of $\mathrm{T} / \mathrm{NK}$ cell lymphoma is confirmed with a battery of immunohistochemical tests. This pathology, although infrequent, should always be considered within the differential diagnoses in ulcerated tumors of this location.

KEY WORDS: Iymphoma, oral manifestations, killers cells.

\section{REFERENCIAS BIBLIOGRÁFICAS}

Cabrera, M. E.; Eizuru, Y.; Itoh, T.; Koriyama, C.; Tashiro, Y.; Ding, S.; Rey, S.; Akiba, S. \& Corvalan, A. Nasal natural killer/T-cell lymphoma and its association with type "i"/Xhol loss strain Epstein-Barr virus in Chile. J. Clin. Pathol., 60(6):656-60, 2007.

Haverkos, B. M.; Coleman, C.; Gru, A. A.; Pan, Z.; Brammer, J.; Rochford, R.; Mishra, A.; Oakes, C. C.; Baiocchi, R. A.; Freud, A. G.; et al. Emerging insights on the pathogenesis and treatment of extranodal NK/T cell lymphomas (ENKTL). Discov. Med., 23(126):189-99, 2017.

Hmidi, M.; Kettani, M.; Elboukhari, A.; Touiheme N. \& Messary, A. Sinonasal NK/T-cell lymphoma. Eur. Ann. Otorhinolaryngol. Head Neck Dis., 130(3):145-7, 2013.

Milián, M. A.; Bagán, J. V.; Jiménez Y. \& Calabuig, C. Linfoma angiocéntrico localizado en paladar. Acta Otorrinolaringol. Esp., 52(6):523-6, 2001.

Neville, B. W.; Damm, D. D.; Allen, C. M. \& Chi, A. C. Oral and Maxillofacial Pathology. St. Louis, Elsevier, 2016. pp.562-3.

Norris, D. WHO Classification of Tumors of Hematopoietic and Lymphoid Tissues. 4th ed. Lyon, Pathol. Newslett., (4), 2012. Available from: http://www.qml.com.au/Portals/0/PDF/ Newsletters/QML_NL_4_2012.pdf

Silvestre, F. J.; Perez-Herbera, A.; Puente-Sandoval, A. \& Bagán, J. V. Hard palate perforation in cocaine abusers: a systematic review. Clin. Oral Investig., 14(6):621-8, 2010.

Tababi, S.; Kharrat, S.; Sellami, M.; Mamy, J.; Zainine, R.; Beltaief, N.; Sahtout, S. \& Besbes, G. Extranodal NK/T-cell lymphoma, nasal type: report of 15 cases. Eur. Ann. Otorhinolaryngol. Head Neck Dis., 129(3):141-7, 2015.

Tlholoe, M. M.; Kotu, M.; Khammissa, R. A.; Bida, M.; Lemmer, J. \& Feller, L. Extranodal natural killer/T-cell lymphoma, nasal type: 'midline lethal granuloma.' A case report. Head Face Med., 9:4, 2013.

Dirección para correspondencia:

Carlos Humeres Sigala

Hospital Regional Antofagasta.

Azapa 5395. Edificio CDT

Unidad de Anatomía Patológica

Antofagasta

CHILE

Email: chumeres@gmail.com

Recibido : 11-04-2019

Aceptado: 01-07-2019 